\title{
Nalbuphine Use for Postoperative Pain in Bariatric Surgery: Case Series and Rationale
}

\author{
A. R. de Oliveira, F. S. Conter, E. S. Martinelli, and A. C. Weston
}

\section{ABSTRACT}

Obesity became an epidemic condition worldwide with a significant impact in healthcare and surgical interventions emerged as a treatment for it. Due to their health conditions, obese population are at higher risk of presenting opioids adverse effects. The goal of this study is to assess the potential use of nalbuphine on bariatric surgery according to its beneficial effect as an agonist-antagonist opioid.

\begin{abstract}
A total of 93 medical records of consecutive patients were selected retrospectively at Santa Casa de Porto Alegre Hospital from January 2018 to January 2019. Patients were overall women, middle-aged, with obesity grade 3 and with stable comorbidities. Sleeve gastrectomy was the main surgery technique by laparoscopic approach. Anesthesia used was essentially TIVA, with Dipyrone and NSAIDS as the main adjuvants associated. The time to the first requirement of nalbuphine (TFRN) and total dose of nalbuphine in 24h (TDN24) had medians of 80 minutes and $20 \mathrm{mg}$, respectively. Respiratory depression, urinary retention and pruritus were not found in any patients. The only data statistically significant was sex related TDN24, with men using almost twice larger median doses than women.

The analgesic properties and adverse effects profile look encouraging in this setting. The female prevalence is a relevant information considering the influence of gender in nalbuphine efficacy. We can see the agreement with this concept observing that the only statistically significant difference in all study was the total dose of nalbuphine in the first $24 \mathrm{~h}$ postoperative, favoring females.
\end{abstract}

Keywords: Nalbuphine, Obesity, Bariatric, Surgery, Pain.
Published Online: November 21, 2020

ISSN: $2593-8339$

DOI: $10.24018 /$ ejmed.2020.2.6.510

\section{A. R. de Oliveira*}

Department of Surgery, Irmandade Santa Casa de Misericórdia Porto Alegre, Brazil.

(e-mail: 4lexandrero7h@ ${ }^{@ m a i l . c o m) ~}$

F. S. Conter

Medical Student, Universidade Luterana do Brasil, Brazil.

(e-mail: francieleconter1@ gmail.com)

E. S. Martinelli

Resident of Anesthesiology - Hospital

Nossa Senhora da Conceição - Porto Alegre, Brazil.

(e-mail: eduardaschutzmartinelli@gmail.com A. C. Weston

Department of Surgery, Irmandade Santa Casa de Misericórdia Porto Alegre, Brazil.

(e-mail: antonioweston@ ${ }^{\circledR}$ terra.com.br)

*Corresponding Author

\section{INTRODUCTION}

Obesity became an epidemic condition worldwide with a significant impact in healthcare. Surgical interventions are one of the main approaches to obese patients because its effects in weight reduction and related diseases, modifying morbimortality outcomes. The perioperative safety should be taken seriously in bariatric surgery as data of mortality could be as high as $9 \%$ in 30 days. Current data of 30-day mortality indicates improved results from $0,3 \%$ to $0,07 \%$, when laparoscopic approach was used [1]-[4].

The anesthesia used for bariatric surgery must be adapted and individualized all the time regarding better outcomes, essentially safety and patient experience [5]-[9]. The recent advances in opioid-free or opioid-spare anesthesia and analgesia are becoming more usual nowadays as part of a strategy to reduce perioperative adverse events related to opioid use like respiratory depression, postoperative nausea and vomiting, ileus, pruritus, urinary retention and also addiction [10], [11].

Nalbuphine was clinically introduced in 1978 with the hope of becoming an effective pain reliever with little abuse potential [12], [13]. It is an opioid with antagonist activity at the mu-receptor and agonist activity at the kappa-receptor that has been successfully used to treat postoperative pain in multiple surgeries settings. The analgesic efficacy of nalbuphine is comparable to morphine, besides nalbuphine provides a better safety profile than morphine [13]-[17].

The goal of this study is to describe for the first time the nalbuphine use in bariatric surgery and compare the data to literature, outlining the rationale of use it, specially relating to pain efficacy and better adverse events profile.

\section{MeTHODS}

A total of 93 medical records of consecutive patients were selected retrospectively at São Francisco Hospital, Irmandade Santa Casa de Misericordia de Porto Alegre (Porto Alegre - Brazil) from January 2018 to January 2019. Nine medical records were rejected for incomplete information. The study was approved by the Ethics Committee of Irmandade Santa Casa de Misericordia de Porto Alegre. 
The patients were submitted to a standard preoperative preparation and standard monitors. Thromboprophylaxis was performed in all patients with mechanical and pharmacological measures (LMWH).

The surgical technique, sleeve gastrectomy or gastric bypass with gastrointestinal Roux-en-Y anastomosis, was based on patient preference, past history, eating behavior and anatomy. The surgery was always initiated by laparoscopic approach. Pneumoperitoneum was setting around $12 \mathrm{mmHg}$. Local anesthesia pre-incisional was performed with ropivacaine $1 \%$ in all patients.

The choice of anesthesia technique was made on individual basis according the anesthesiologist preference. Inhalational always performed with Sevoflurane (Abbott Laboratories Argentina S.A. Buenos Aires - Argentina) and Total Intravenous Anesthesia (TIVA) with Propofol (Diprivan PFS, AstraZeneca UK Limited - Macclesfield Cheshire - UK). Remifentanil (GlaxoSmithKline Manufacturing S.P.A. (PR) - Parma - Italia) was administered continuously from the induction of anesthesia until the suture stitch at doses ranging from $0,15 \mathrm{mcg} / \mathrm{kg} / \mathrm{min}$ to $0,3 \mathrm{mcg} / \mathrm{kg} / \mathrm{min}$. Neuromuscular blockade was performed using Rocuronium (CRISTÁLIA - Produtos Químicos Farmacêuticos Ltda. Butantã - SP) $1,2 \mathrm{mg} / \mathrm{kg}$ at induction and complementary doses administered to kept TOF (Trainof-four) 0 and PTC (Post tetanic count) maximum 2. Dexamethasone (Biosintética Farmacêutica Ltda. São Paulo - SP) and Ondansetron (GlaxoSmithKline Australia Pty Ltd. Boronia - Australia) were administered to all patients. Other adjuvants like NSAIDS (Tenoxicam, Ketoprofen or Ketorolac - União Química Farmacêutica Nacional S/A. Pouso Alegre - MG), Dipyrone (Sanofi-Aventis Farmacêutica Ltda. Suzano - SP), S(+)ketamine, Lidocaine and Clonidine (CRISTÁLIA - Produtos Químicos Farmacêuticos Ltda. Butantã - SP), and Dexmedetomidine (Hospira Inc. Rocky Mount - North Carolina - USA) were administered in individual basis according to the anesthesiologist preference. At the end of surgery all patients received a bolus dose of Nalbuphine (CRISTÁLIA Produtos Químicos Farmacêuticos Ltda. Butantã - SP) 0,1 $\mathrm{mg} / \mathrm{kg}$ based on total body weight (TBW). All patients had neuromuscular blockade reversal with Sugammadex (Organon (Ireland) Ltd. Swords - Ireland) at the end of the surgery (TOF $>0,9$, count 4 and no fade) and were extubated in the operation room.

Following surgery, patients were admitted at Post Anesthesia Care Unit (PACU) and maintained in a semisitting position. NSAIDS and dipyrone were prescribed in fixed intervals and nalbuphine in PRN. The analgesia endpoints were time to first requirement of nalbuphine (TFRN) and total dose of nalbuphine in 24h (TDN24). Adverse reactions evaluated: postoperative nausea and vomiting (PONV), pruritus, respiratory depression (respiratory frequency less than 10 breaths per minute and/or $\mathrm{SpO}_{2}<92 \%$ ), sedation (Ramsay Scale), urinary retention (inability to urinate despite having a full bladder). The length of stay at the recovery room was fixed in 2 hours for Institutional request. No patient was recovered at ICU.

Statistical analysis was performed using SPSS (Version 20, SPSS Inc., Chicago). Countable data were expressed as frequencies and percentage (\%), and comparison of groups was performed using the Chi-square test and Fisher's exact probability method. The normality of data was assessed by the Kolmogorov Smirnov test. Continuous data with a normal distribution are presented as mean and standard deviation, and data that did not have a normal distribution are described with the median and interquartile range (25-75). The independent Student t-test for symmetrical data and Mann Whitney for asymmetrical data were used. The Spearman's (non-parametric) correlation were applied when indicated. In all cases, $p<0.05$ was considered to be statistically significant.

\section{RESUlts}

General information including age, gender, BMI, ASA status and comorbidities are shown in Table 1 . The patients are predominant women, middle-aged, with obesity grade 3 (BMI < 49,9) with stable comorbidities (ASA 2 - 96,5\%).

\begin{tabular}{cc}
\multicolumn{2}{c}{ TABLE 1: PATIENT DEMOGRAPHIC } \\
\hline Female; $\mathrm{n}(\%)$ & $\mathbf{6 6}(\mathbf{7 8 , 6 )}$ \\
Mean age, years \pm SD & $38,6 \pm 10,6$ \\
Mean BMI \pm SD & $42,5 \pm 5,6$ \\
ASA status 2; n (\%) & $82(96,5)$ \\
Arterial Hypertension, n (\%) & $36(42,9)$ \\
Depression, n (\%) & $18(21,4)$ \\
Diabetes mellitus, n (\%) & $15(17,9)$ \\
Obstructive Sleep Apnea, n(\%) & $13(15,5)$ \\
Chronic Pain, n (\%) & $12(14,3)$ \\
Hypothyroidism, n(\%) & $7(8,3)$ \\
Asthma, $\mathrm{n}(\%)$ & $3(3,6)$ \\
Cancer, $\mathrm{n}(\%)$ & $1(1,2)$ \\
Tobacco use, $\mathrm{n}(\%)$ & $1(1,2)$ \\
Stroke; $\mathrm{n}(\%)$ & $1(1,2)$ \\
Miscellaneous, $\mathrm{n}(\%)$ & $6(7,1)$ \\
\hline
\end{tabular}

ASA, American Society of Anesthesiologists; BMI, body mass index in $\mathrm{Kg} / \mathrm{m}^{2} ; \mathrm{SD}$, standard deviation.

Descriptive characteristics are presented in Table 2 and show sleeve gastrectomy as the main surgery technique $(82,3 \%)$ by laparoscopic approach $(96,5 \%)$ with a duration around 80 minutes. Anesthesia used was essentially TIVA (81\%), with dipyrone $(96,4 \%)$ and NSAIDS $(90,5 \%)$ as the main adjuvants associated. TFRN and TDN24 had medians of 80 minutes (30-180 $\mathrm{min})$ and $20 \mathrm{mg}(12-37 \mathrm{mg}$ ), respectively.

Respiratory depression, urinary retention and pruritus were not found in any patients. Only one patient that previously had obstructive sleep apnea (OSA) and used CPAP therapy at home needed to use the equipment in the immediate postoperative period. The same patient became agitated (Ramsay 1) and present stable supraventricular tachycardia at the end of surgery and at PACU for 30 minutes after CPAP was installed with spontaneous resolution.

The only data statistically significant was sex related TDN24, with men using almost twice larger median doses than women (Table 3). There was no other parameter statistically related to PONV, TFRN or TDN24 (Tables 3, 4, 5 and 6). 
TABLE 5: RELATION CHARACTERISTICS AND PONV

\begin{tabular}{cc}
\hline Time to First Nalbuphine Dose (min), median \pm IQR & $\mathbf{8 0}(\mathbf{3 0 - 1 8 0})$ \\
Total Dose Nalbuphine 24h (mg), median \pm IQR & $20(12-37)$ \\
Mean Surgical Duration, min \pm SD & $80,1 \pm 27,3$ \\
Surgical Technique Sleeve, n (\%) & $70(82,3)$ \\
Laparoscopic Approach, n (\%) & $82(96,5)$ \\
Anesthesia Technique, n (\%) & \\
TIVA & $68(81)$ \\
Inhalational & $16(19)$ \\
PONV 24h n (\%) & $20(23,2)$ \\
NSAIDS, n (\%) & $76(90,5)$ \\
Lidocaine, n (\%) & $8(9,5)$ \\
Dexmedetomidine, $\mathrm{n}(\%)$ & $14(16,7)$ \\
Clonidine, n (\%) & $11(13,1)$ \\
Ketamine, n (\%) & $26(31,0)$ \\
Dipyrone, n (\%) & $81(96,4)$ \\
\hline
\end{tabular}

IQR: Interquartile Range (P25-P75). TIVA: Total Intravenous Anesthesia. PONV: Postoperative Nausea and Vomiting. NSAIDS: Nonsteroidal antiinflammatory drugs. *requiring antiemetic drug.

TABLE 3: RELATION BETWEEN CHARACTERISTICS AND TFRN AND TDN24

\begin{tabular}{|c|c|c|c|c|}
\hline Characteristics & TFRN & $\mathbf{P}$ & TDN24 & $\mathbf{P}$ \\
\hline Age & $r_{s}=-0,07$ & 0,559 & $r_{s}=-0,17$ & 0,142 \\
\hline Gender & & 0,661 & & $0,026^{*}$ \\
\hline Female & $75(30-180)$ & & $22(13-40)$ & \\
\hline Male & $80(30-180)$ & & $12(4-25)$ & \\
\hline BMI & $r_{s}=0,01$ & 0,974 & $r_{s}=0,13$ & 0,250 \\
\hline Preoperative Diseases & & 0,529 & & 0,987 \\
\hline Yes & $60(30-180)$ & & $20(12-40)$ & \\
\hline No & $120(30-360)$ & & $22(10-33)$ & \\
\hline Anesthesia & & 0,810 & & 0,727 \\
\hline 1 & $70(30-188)$ & & $20(12-35)$ & \\
\hline 2 & $90(45-180)$ & & $19(12-33)$ & \\
\hline NSAIDS & & 0,911 & & 0,361 \\
\hline Yes & $90(30-180)$ & & $20(12-36)$ & \\
\hline No & $60(38-270)$ & & $30(20-40)$ & \\
\hline Lidocaine & & 0,975 & & 0,714 \\
\hline Yes & $60(38-315)$ & & $30(4-40)$ & \\
\hline No & $90(30-180)$ & & $20(12-34)$ & \\
\hline Dexmedetomidine & & 0,892 & & 0,756 \\
\hline Yes & $120(30-240)$ & & $25(13-38)$ & \\
\hline No & $70(30-180)$ & & $20(12-37)$ & \\
\hline Clonidine & & 0,862 & & 0,385 \\
\hline Yes & $135(30-210)$ & & $28(17-52)$ & \\
\hline No & $60(30-180)$ & & $20(12-34)$ & \\
\hline Ketamine & & 0,546 & & 0,335 \\
\hline Yes & $60(30-180)$ & & $19(12-33)$ & \\
\hline No & $100(34-180)$ & & $21(12-40)$ & \\
\hline Dipyrone & & 0,209 & & 0,886 \\
\hline Yes & $85(30-180)$ & & $20(12-36)$ & \\
\hline No & $15(15-15)$ & & $28(10-28)$ & \\
\hline \multicolumn{5}{|c|}{$\begin{array}{l}\text { Time to first requirement of Nalbuphine (TFRN) and Total dose of } \\
\text { Nalbuphine in } 24 \mathrm{~h} \text { (TDN24). }\end{array}$} \\
\hline \multicolumn{5}{|c|}{ TABLE 4: RELATION SURGERY TECHNIQUE AND PONV IN 24H } \\
\hline & Nausea & $\mathbf{P}$ & Vomiting & $\mathbf{P}$ \\
\hline $\begin{array}{c}\text { Surgery } \\
\text { Duration (min) }\end{array}$ & $83 \pm 27 / 78 \pm 28$ & 0,428 & $85 \pm 27 / 78 \pm 28$ & 0,370 \\
\hline Sleeve & & 0,766 & & 0,999 \\
\hline Yes & 32,4 & & 23,5 & \\
\hline No & 25,0 & & 25,0 & \\
\hline Bypass & & 0,768 & & 0,747 \\
\hline Yes & 26,7 & & 26,7 & \\
\hline No & 31,9 & & 23,2 & \\
\hline
\end{tabular}

\begin{tabular}{|c|c|c|c|c|}
\hline Characteristics & Nausea & $\mathbf{P}$ & Vomiting & $\mathbf{P}$ \\
\hline Age & $36 \pm 10 / 40 \pm 11$ & 0,171 & $37 \pm 11 / 39 \pm 11$ & 0,401 \\
\hline Sex & & 0,538 & & 0,542 \\
\hline Female & 33,3 & & 25,8 & \\
\hline Male & 22,2 & & 16,7 & \\
\hline BMI & $43 \pm 6 / 42 \pm 5$ & 0,545 & $43 \pm 7 / 42 \pm 5$ & 0,379 \\
\hline Comorbidities & & 0,208 & & 0,245 \\
\hline Yes & 26,2 & & 19,7 & \\
\hline No & 43,5 & & 34,8 & \\
\hline Anesthesia & & 0,765 & & 1,000 \\
\hline TIVA & 31,2 & & 25,0 & \\
\hline Inhalation & 25,0 & & 25,0 & \\
\hline NSAIDS & & 0,425 & & 0,673 \\
\hline Yes & 32,9 & & 25,0 & \\
\hline No & 12,5 & & 12,5 & \\
\hline Lidocaine & & 0,425 & & 0,189 \\
\hline Yes & 12,5 & & - & \\
\hline No & 32,9 & & 26,3 & \\
\hline Dexmedetomidine & & 0,533 & & 0,999 \\
\hline Yes & 21,4 & & 21,4 & \\
\hline No & 32,9 & & 24,3 & \\
\hline Clonidine & & 0,999 & & 0,999 \\
\hline Yes & 27,3 & & 18,2 & \\
\hline No & 31,5 & & 24,7 & \\
\hline Ketamine & & 0,780 & & 0,349 \\
\hline Yes & 26,9 & & 15,4 & \\
\hline No & 32,8 & & 27,6 & \\
\hline Dipyrone & & 0,999 & & 0,999 \\
\hline Yes & 30,9 & & 24,7 & \\
\hline No & 33,3 & & - & \\
\hline
\end{tabular}

TABLE 6: RELATION SURGERY CHARACTERISTICS AND TFRN/ TDN24

\begin{tabular}{ccccc}
\hline \multicolumn{1}{c}{ TFRN } & P & TDN24 & P \\
\hline Surgery & $\mathrm{r}_{\mathrm{s}}=0,07$ & 0,545 & $\mathrm{r}_{\mathrm{s}}=-0,08$ & 0,497 \\
$\begin{array}{c}\text { Duration } \\
\text { Sleeve }\end{array}$ & & 0,232 & & 0,985 \\
Yes & $60(30-180)$ & & $20(12-39)$ & \\
No & $120(60-180)$ & & $20(12-30)$ & \\
By-pass & & 0,301 & & 0,854 \\
Yes & $105(60-210)$ & & $20(12-33)$ & \\
No & $60(30-180)$ & & $20(12-39)$ & \\
\hline
\end{tabular}

Time to first requirement of Nalbuphine (TFRN) and Total dose of Nalbuphine in 24h (TDN24).

\section{DISCUSSION}

In this study we can show for the first time the use of nalbuphine in bariatric surgery. The analgesic properties and adverse effects profile look encouraging in this setting, as already theoretical considered by the author in previous article [18]. Since our data of TDN24 is similar to literature and adverse effects like respiratory depression, sedation, pruritus, urinary retention and PONV appear to be mureceptor-mediated [15], nalbuphine should not often cause apnea, nausea or emesis, as we were able to confirm on this study.

The demographic data are similar to literature [19], [20], [22], [23]. Even though sleeve gastrectomy was the preferred technique in contrast to gastric bypass, differently from literature [4], [8], laparoscopic approach was used on overall patients, assuring the improvement of post operative, with less pain and morbidity [10].

The female prevalence is a relevant information considering the influence of gender in nalbuphine efficacy. We can see the agreement with this concept observing that the only statistically significant difference in all study was the total dose of nalbuphine in the first $24 \mathrm{~h}$ postoperative, favoring females. A lot of evidence demonstrate increase responsivity of women to nalbuphine, contrary to the 
evidence of lower responsivity of women to mu-opioid agonists. The sex-linked mechanisms in kappa-opioid receptor (KOR) mediated opioid analgesia involve the $\mathrm{N}$ methyl-D-aspartate receptors (NMDARs) in males (NMDAR antagonists block KOR analgesia) and the melanocortin-1 receptors (MC1Rs) in females. (MC1Rs are necessary for KOR analgesia in females). Another mechanism could be opioid-mediated analgesia does not require concomitant activation of mu-kappa heterodimers receptors in males, whereas activation of them is necessary in females [21].

Nalbuphine is clinically indicated for mild to moderate pain and it is distinguished from other analgesic agonistsantagonists for having a greater antagonist activity and a lesser behavioral effect in the organism. Even though our data shows a multimodal anesthesia technique, we can see on Table 3 that TFRN and TDN24 were not related to any drug used on perioperative. The patients were treated equally on post operative with nalbuphine, when asked, dipyrone $(96,4 \%)$ and NSAIDS $(90,5 \%)$ as soon as this should not be a bias of this study.

It produces its analgesic and sedative effect through the kappa-opioid receptor and may, due to its mixed properties, mitigate the adverse effects related to the mu-opioid receptor. Besides, drugs related to KOR are less capable causing addiction on patients [13], [14]. As we already know, women have more KOR available and effective than men. When comparing nalbuphine to morphine, it is stated that it is an equally effective alternative to morphine in the analgesia of patients undergoing minor gynecological surgery [23], as well as cholecystectomy [24], yet both studies could have a bias, since women were the whole or the majority of the sample, respectively. In a study carried out with a group of only male patients, the study had to be stopped after the sample of six male patients had inadequate analgesia with nalbuphine after abdominal surgery, confirming the lower effectiveness of this opioid in men [25].

We can see that the use of nalbuphine on bariatric surgery is promising: less side effects, less addiction and equianalgesic to morphine [16]-[18]. These are important features of an opioid especially for certain populations, like those who are at higher risk for developing respiratory depression. The main concern we may have on the use of nalbuphine is when our sample is mostly composed of men, as we know the limiting use of this drug on this gender [18]. Also, like other mixed agonists-antagonists, nalbuphine exhibits a ceiling effect. Increasing doses of drug produce increasing intensity of analgesia only up to a point; beyond that point, further increases in dose do not result in increased intensity of analgesia, which is bounded for excruciating pain but safer for opioid side effects on risky populations [15]. Moreover, we can expect an improvement on our post operative care due to its qualities instead of morphine.

This initial observational study aimed to provide data to plan a randomized, double blind, compared against morphine study with $80 \%$ power.

\section{APPENDIX}

Surgery duration represented as mean $\pm \mathrm{SD}$ in groups with/without outcome using the independent Nausea and vomiting compared using the Chi-square test and Fisher's exact probability method. PONV: Postoperative Nausea and Vomiting.

Age and BMI represented as mean \pm SD in groups with/without outcome using the independent Nausea and vomiting compared using the Chi-square test and Fisher's exact probability method. PONV: Postoperative Nausea and Vomiting.

\section{ACKNOWLEDGMENT}

We thank all the surgical team, especially Dr Rodrigo Koprovski Menger, Dr Rodrigo Mariano and Dr Gunther Ayala.

\section{REFERENCES}

[1] Buchwald H, Estok R, Fahrbach K, Banel D, Sledge I. Trends in mortality in bariatric surgery: A systematic review and meta-analysis. Surgery, 2007; 142(4): 621-35.

[2] Sjöström L, et al. Effects of Bariatric Surgery on Mortality in Swedish Obese Subjects. N Engl J Med, 2007; 357: 741-52.

[3] Tsai A, Schumann R. Morbid obesity and perioperative complications. Curr Opin Anesthesiol, 2016; 29:103-8.

[4] DeMaria EJ, et al. Baseline data from American Society for Metabolic and Bariatric Surgery-designated Bariatric Surgery Centers of Excellence using the Bariatric Outcomes Longitudinal Database. Surg Obes Relat Dis. 2010 Jul-Aug; 6(4): 347-55.

[5] Baerdemaekera L \& Margarson M. Best anaesthetic drug strategy for morbidly obese patients. Curr Opin Anesthesiol, 2016; 29: 119-28.

[6] Soleimanpour $\mathrm{H}$, et al. Anesthetic Considerations in Patients Undergoing Bariatric Surgery: A Review Article. Anesth Pain Med. 2017 Aug; 7(4): e57568.

[7] Pieracci FM, Barie PS, Pomp A. Critical care of the bariatric patient. Crit Care Med, 2006 Jun; 34(6): 1796-804.

[8] Helling TS, Willoughby TL, Maxfield DM, Ryan P. Determinants of the need for intensive care and prolonged mechanical ventilation in patients undergoing bariatric surgery. Obes Surg, 2004; 14(8): 103641

[9] Cend JC, et al. Utilization of intensive care resources in bariatric surgery. Obes Surg, 2005; 15(9): 1247-51.

[10] Juvin P, et al. Post-operative course after conventional or laparoscopic gastroplasty in morbidly obese patients. Eur J Anaesthesiol, 1999; 16(6): 400-3.

[11] Poulose BK, et al. National analysis of adverse patient safety events in bariatric surgery. Am Surg, 2005; 71(5): 406-13.

[12] Beaver WT, Feise GA. A comparison of the analgesic effect of intramuscular nalbuphine and morphine in patients with postoperative pain. J Pharmacol Exp Ther, 1978; 204: 487-96.

[13] Mazak K. Physico-chemical profiling of semisynthetic opioids. Journal of Pharmaceutical and Biomedical Analysis, 2017; 135: $97-$ 105.

[14] Zacny JP, Conley K, Marks S. Comparing the subjective, psychomotor and physiological effects of intravenous nalbuphine and morphine in healthy volunteers. J Pharmacol Exp Ther, 1997; 280: 1159-69.

[15] Gunion MW, Marchionne AM, Anderson CTM. Use of the mixed agonist-antagonist nalbuphine in opioid based analgesia. Acute Pain, 2004; 6: 29-39.

[16] Mendes FF, et al. Is Nalbuphine a better option than morphine in post ambulatory videolaparascopic colecistectomy? Random double blind study. REV DOR 2004; 5(4): 389-94.

[17] Zeng Z, et al. A Comparision of Nalbuphine with Morphine for Analgesic Effects and Safety: Meta-Analysis of Randomized Controlled Trials. Sci Rep 2015; 5:10927.

[18] Oliveira ARD, Weston AC, Martinelli ES. May We Consider the Use of Nalbuphine as Postoperative Opioid in Bariatric Patients? J Anesth Crit Care Open Access, 2016; 4(5): 00159.

[19] English WJ, et al. American Society for Metabolic and Bariatric Surgery 2018 estimate of metabolic and bariatric procedures 
performed in the United States. Surg Obes Relat Dis, 2020; 16(4): 45763.

[20] Minai FN, Khan FA. A comparison of morphine and nalbuphine for intraoperative and postoperative analgesia. J Pak Med Assoc, 2003; 53:391-96.

[21] Chartoff EH, Mavrikaki M. Sex Differences in Kappa Opioid Receptor Function and Their Potential Impact on Addiction. Front Neurosci, 2015; 9: 466.

[22] Culebras X, Gaggero G, Zatloukal J, Kern C, Marti RA. Advantages of intrathecal nalbuphine, compared with intrathecal morphine, after cesarean delivery: an evaluation of postoperative analgesia and adverse effects. Anesth Analg, 2000; 91: 601-5.

[23] Pinnock CA, Bell A, Smith G. A comparison of nalbuphine and morphine as premedication agents for minor gynaecological surgery. Anaesthesia, 1985; 40: 1078-81.

[24] Bahar M, Rosen M, Vickers MD. Self-administered nalbuphine, morphine and pethidine. Comparison, by intravenous route, following cholecystectomy. Anaesthesia, 1985; 40(6): 529-32.

[25] Pugh GC, Drummond GB. A dose-response study with nalbuphine hydrochloride for pain in patients after upper abdominal surgery. $\mathrm{Br}$ Journal Anesthesiology, 1987; 59(11): 1356-63. 